\title{
State Obligation towards the Fulfillment of the Right to Health: A Study in Bangladesh Perspective
}

\author{
Md. Jalal Uddin \\ Senior Lecturer, Department of Law, Metropolitan University, Sylhet \\ Suraya Momtaz
}

Senior Lecturer, Department of Law, Southern University Bangladesh

Mohammad Saidul Islam

Assistant Professor, Department of Law, International Islamic University Chittagong

E-Mail: islamm.saidul@yahoo.com

\section{Doi:10.5901/mjss.2013.v4n13p73}

\section{Abstract}

Sound growth of a human being pivots around his sound health required not only for a human being himself, but also for the entire society and thus the State itself. It is one of Economic, Social and Cultural rights otherwise conceded as basic need which a State is legally committed to ensure its citizens. In addition to international obligation, there are around 45 domestic laws in force in Bangladesh providing for health in any way or the other and to serve the purpose, and the government accordingly takes various steps expected to be duly targeted to place the people in the position to have an affordable and easy access to the health service. But uncertainty in authoritatively determining the concrete elements of health, insufficiency of the health facilities and budget allocation for health service, non-accountability of health professionals, corruption, profit motivated health care service, lack of political will and mass-participation in the health administration, preference of unproductive sector, and extreme difference in terms of economic status are inter alia the key factors to narrow it down to the extent enough to leave the commitment amounting to obligation on the part of the State and the expectation to right possessed by the people to remain a mere rhetoric.

\section{Introduction}

Bangladesh, with over 150 million population most of whom reside in the rural area, is located on the northern shore of the Bay of Bengal, covering 147,570 square $\mathrm{km}$ with the ever remaining risk of natural calamities, like floods, cyclones, epidemics, etc. It has a health system dominated by the public sector and the private sector is run by local entrepreneurs, different NGOs and international organizations. In public sector, the Ministry of Health and Family Welfare (MOHFW) is the leading organization for policy formulating, planning and decision making at macro and micro level. Since its independence to improve the situation as per its constitutional commitment relating to health related obligation, Bangladesh has adopted various initiatives such as legislations ${ }^{1}$, programs, plans, policies, projects and reforms. In the absence of a formal health policy, all health-related planning and programming were guided by the health sector components of several successive Five Year Plans the first of which was introduced in 1973 and the fifth and last one in1997 to materialize certain objectives which were inter alia developing health delivery service system so as to benefit the entire population, particularly the common men, encouraging the private sector and the NGOs to share some responsibilities for reaching healthcare services to the masses, ensuring at least a minimum level of healthcare to all, introducing a process of integration between health and population sector activities by different programs like a new

\footnotetext{
${ }_{1}^{1}$ There are 45 laws, in force in the country, which have been identified to deal directly with the protection of human health, while scattered provisions are also there in other laws having bearing on health. See generally Farooque, Mohiuddin and Hasan, S. Rizwana: Laws Regulating Environment in Bangladesh, 2nd ed. Dhaka, published by Bangladesh Environmental Lawyers Association, 2004, p. 60.
} 
range of programs such as the Expanded Programme on Immunization (EPI), vitamin A distribution etc ${ }^{2}$. This paper attempts to highlight Bangladesh's performance on the implementation of the right to health with reference to its obligation assumed thereby under both the domestic and international laws and then identify the problems in the access for the people to the health service.

\subsection{What is Health?}

An understanding of health is the basis of all health care but it has not resulted in the formulation of a universally accepted definition of health, rather health is perceived in the different ways by biomedical scientists, social science specialists, health administrators and ecologists and this gives rise to confusions about the concept of health ${ }^{3}$. The ecologists put forward an attractive hypothesis which viewed health as a dynamic equilibrium between man and his environment and disease a maladjustment of human organism to environment ${ }^{4}$. R. Dubos defines health as implying the "relative absence of pain and discomfort and continuous adaptation and adjustment to the environment to ensure optimal function". Human ecological and cultural adaptations do determine not only the occurrence of disease but also the availability of food and population explosion, i.e., improvement in human adaptation to natural environments can lead to longer life expectancies and a better quality of life even in the absence of modern health delivery services ${ }^{5}$. According to social scientists, health is something more than a mere biomedical phenomenon and influenced by social, psychological, cultural, economic and political factors of the people concerned ${ }^{6}$. Different types of perception, as stated above, represent that health is not an isolated concept, but one having various aspects to be considered in defining health. Thus, health is a unified and comprehensive process involving the totality of well being of a human being in the context of his environment and implies a sound mind, in a sound body, in a sound family, in a sound environment?.

\subsection{Right to Health}

The right to health is not to be understood as the right to be healthy. Such right entails the right to the enjoyment of a variety of facilities, goods, services and conditions necessary for the realization of the highest attainable standard of health. The right includes rights to both healthcare and the underlying determinants of health, including access to potable water, adequate and safe food, adequate sanitation and housing, healthy occupational and environmental conditions, and access to health-related information and education ${ }^{8}$. The right to health contains both freedoms and entitlements. The freedoms include the right to control one's body, including reproductive health, and the right to be free from interference, such as freedom from torture and non-consensual medical treatment. The entitlements include a system of healthcare and protection that is available, accessible, acceptable, and of good quality. Thus, the right to health implies that functioning public health and health care facilities, goods and services are available in sufficient quantity within a state. It also means that they are accessible to everyone without discrimination. Accessibility has a number of dimensions, including physical, informational and economic accessibility. Thus, information accessibility includes the right to seek service and impart information concerning health issues, subject to the right to have personal health data treated with confidentiality. Economic accessibility means that health facilities, goods and services must be affordable for all. Further, all health facilities, goods and services must be acceptable, i.e., respectful of medical ethics and be culturally appropriate and of good quality9 .

\subsection{Right to Health and Right to Life}

The right to life is guaranteed in the Bangladesh Constitution as one of fundamental rights. Article 32 provides that no

\footnotetext{
${ }^{2}$ Chowdhury, Omar Haider, and Osmani, S.R. (March-June 2010,) 'Towards Achieving the Right to Health: the Case for Bangladesh', The Bangladesh Development Studies, Vol. XXXIII, Nos. 1 \& 2, <http://www.bids.org.bd/bds/33-1\&2/Omar_H_\&_S_R_Osmani.pdf> (Accessed on 29.05.2011) pp. 6 \& 7.

${ }^{3}$ Kumar, Avanish, Human Right to Health, 1'st edition, Satayam Law International , new Delhi, India, 2007, p. 15.

${ }^{4}$ Kumar, Avanish, supra note 3, p.16.

5 Quoted in K. Park, supra note 4, p.11.

${ }^{6}$ Supra note 4, p.12.

7 Supra note 3, p.17.

${ }^{8}$ Chowdhury, Omar Haider, and Osmani, S.R., supra note 2, p.4.

${ }_{9}$ Chowdhury, Omar Haider, and Osmani, S.R., supra note 2, pp.4 \& 5.
} 
person shall be deprived of life save in accordance with law. But the right to health is not so recognized; in the constitution, what is dealt with the right to health is inclusion thereof in the constitution as one of the state programs named as principles of state policy which are not judicially enforceable ${ }^{10}$. But certain issues regarding what constitute and facilitate life occur to one's prudent mind. What is life? What is right to life? What is intended in articles 31 and 32 of the constitution which do not explicitly define the term life embracing the basic components of life? Is it confined mere right not to be killed? Does the deprivation of the right to health amounts to indirect killing? The above mentioned issues were attempted to be settled by the judiciary, an appropriate forum in a state, and its earlier view was not satisfactory and thus, the Appellate Division ${ }^{11}$ held that, "It is the law of the constitution itself that the fundamental principles of state policy are not laws themselves but principles. To equate "principles" with laws is to go against the constitution itself"12 (per Mustafa Kamal J.) (Italics supplied). S. Ahmed, Chief justice held these principles to be non-enforceable, stating -"They are in the nature of the people's program for socio-economic development of the country in peaceful manner, not overnight, but gradually. Implementation of these programs requires resources, technical know-how and many other things including mass-education." ${ }^{13}$ (Italics supplied). But subsequently the judiciary has shifted from its traditional exposition and the response therefrom relating to fundamental principles of state policy is praiseworthy and devised a new tool to give remedy. Thus the court held In Wahab vs. Secretary, Ministry of Land that although not judicially enforceable the fundamental principles of state policy cast an obligation upon the government to act on them ${ }^{14}$. Besides, the liberal interpretation of the term 'life' may be used as a tool to enforce the right to health. Thus, Field J. held that life within the meaning of Article 31 means something more than mere animal existence ${ }^{15}$, but includes a right to protection of health ${ }^{16}$. (Italics supplied). The view of the Indian Supreme court as to the meaning of the right to life is much clearer and may be used as a beacon to persuade our judiciary. Thus the Indian Supreme court held in -

a. Keshavnand Bharti Vs. State of Kerala that directive principles of state policy should enjoy the same status as traditional fundamental rights ${ }^{17}$;

b. Bandhua Mukti Morcha Vs. UOI that to live with human dignity included the right to good health ${ }^{18}$;

c. Consumer Education and Research Centre Vs. UO/19 that the right to health was an integral part of a meaningful right to life and the right to health and medical care is a fundamental right under Article 21, and used the right to life to secure the right to emergency medical care concluding that such an essential obligation could not be avoided by pleading financial constraints ${ }^{20}$. (Italics supplied).

On analysis of the different landmark judgments it has been clear that now the interdependence of all human right is recognized not only in the international forum dealing with human rights, but also in the domestic tribunals and the traditional view which represented isolated view is going to be archaic and a new era to begin to ensure full life for a Human being.

\subsection{State Obligation and Commitment in Health}

Health care is no longer a mere need rather widely recognized by international and national legal instruments. There are so many international and national legal instruments as to justify the state obligation to ensure sound health for its citizens. Article 25 of the Universal Declaration of Human Rights, $1948^{21}$ states "Everyone has the right to a standard of living adequate for ... health and well-being of himself and his family, including ......... housing, medical care and necessary social services, and the right to security in the event of ... sickness, disability.... Motherhood and childhood are entitled to special care and assistance...." Article 12 International Covenant on Economic, Social and Cultural Rights,

\footnotetext{
${ }^{10}$ Article 8(2), the Constitution of the People's Republic of Bangladesh.

${ }^{11}$ Appellate Division is the apex forum of the Bangladesh Judiciary established by article 94 of its constitution.

12 Kudrat-E-Elahi Vs. Bangladesh, 44 DLR (AD) 319.

13 Kudrat-E-Elahi Vs. Bangladesh, 44 DLR (AD) 331.

141 MLR 338, cited in Islam, Mahmudul, Constitutional Law of Bangladesh, $2^{\text {nd }}$ ed. Dhaka, 2002, p. 52.

15 Munn Vs. People of Illinois, 94 US 113, quoted in Islam, Mahmudul, supra note 14, p.187.

${ }^{16}$ Dr. Mohiuddin Farooque Vs. Bangladesh, 48 DLR, 438 (health hazards), quoted in supra note 14, p. 188.

17 (1973) 4 sec 225, quoted in Avanish, supra note 3, p. 171.

18 AIR 1984 SC. 812, quoted in Avanish, supra note 3, p. 177.

${ }^{19}$ AIR, 1995 SC 636, quoted in Avanish, supra note 3, pp. 177 \& 178. (Article 21 of the Indian Constitution corresponds to article 31 of the Bangladesh Constitution).

20 Paschim Bangla Khet Mazdoor Samity and Others Vs. State of West Bengal and Another, (1996), 4 sec 37, Supra note 3, p. 178.

21 The Declaration has been widely and much followed by the States in adopting their new constitution, legislation and in running their diplomatic dealings among them in the international arena. This fact has elevated the Declaration to a customary international law.
} 
$1966^{22}$ lays down-"States Parties shall take all appropriate measures to eliminate discrimination against women in the field of health care in order to ensure, on a basis of equality of men and women, access to health care services, including those related to family planning." In addition, the constitution provides that "it shall be fundamental responsibility of the state to attain......... a constant increase of steady improvement in the material and cultural standard of living of the people, with a view to securing to its citizens-the provisions of basic necessities of life, including food..........medical care" ${ }^{23}$. The constitution further provides that the state shall regard the raising of the level of nutrition and the improvement of the public health as among its primary duties ${ }^{24}$. Thus, there is a strong constitutional commitment, coupled with clear legal obligation to protect human rights in general and political, economic and social rights in particular. The state has, in fact, developed a far reaching and extensive health care infrastructure to that end.

\section{Existing Health Service Delivery System in Bangladesh}

The existing health service delivery system is mainly composed of public and private providers. In addition, there are traditional (Ayurvedi, Kabiraji) and homeopathic providers, NGOs and other non-profit facilities, and qualified and unqualified drug sellers ${ }^{25}$. The public provider, i.e., the government sector provides both preventive and curative service, the private sector provides mainly curative service, and the NGO sector provides mainly preventive service and some basic care ${ }^{26}$. The pattern of Bangladesh's public health service delivery system is hierarchically structured from the national level to the village level. The structure is based on a top down approach. All the decisions regarding health policy formulation, service delivery mechanisms, allocation and utilization of resources etc. are taken at the central level, while the lower level organizations carry out the decisions. Different levels of health institutions, hospitals, health centers provide different public health care services to the beneficiaries ${ }^{27}$.

\subsubsection{National Level}

The supervisory control vests in two directorates, the Directorate General of Health Services (DGHS) and the Directorate General of Family Planning (DGFP), under the Ministry of Health and Family Welfare (MOHFW). The ministry is responsible for policy formulation and decision making, whereas the directorates have the responsibility for planning and implementation of programs and projects. Both directorates provide necessary professional and technical guidance to the Ministry ${ }^{28}$.

\subsubsection{Regional Level}

Within Bangladesh's seven divisions, there are fourteen medical college hospitals ${ }^{29}$ and six Post-graduate Hospitals and 25 Specialized Hospitals to provide tertiary health care across the nation and also to work as referral institutions for the districts for the treatment of difficult and complicated cases ${ }^{30}$. These are all teaching hospitals, which have bed capacities varying from 250-1050, of which a maximum number of beds are free. The divisional health authority is the functional unit at the divisional level headed by a divisional health director ${ }^{31}$.

\subsubsection{District Level}

\footnotetext{
${ }^{22}$ Bangladesh is one of the states signatory to the Covenant and ratified the same in 1999, and thereby has reinforced its obligation to provide adequate health care for its citizens.

${ }^{23}$ Article 15 of the Constitution of the People's Republic of Bangladesh.

${ }^{24}$ Article 18, ibid.

${ }^{25}$ Chowdhury, Omar Haider, and Osmani, S.R., Supra note 2, p.15.

26 Ibid, p.16.

27 Islam, Mohammad Shafiqul and Ullah, Mohammad Woli, (June 2009) 'People's Participation in Health Services: A Study of Bangladesh's Rural Health Complex' in Bangladesh Development Research Working Paper Series, BDRWPS 7 <http://www.bangladeshstudies.org/files/WPS_no7.pdf > (Accessed on 26.05.2011), p.6.

28 Islam, Mohammad Shafiqul and Ullah, Mohämmad Woli, supra note 27, p.7.

29 Islam, Mohammad Shafiqul and Ullah, Mohammad Woli, supra note 27, p.7.

${ }^{30} \mathrm{Ahmad}$, Alia, 'Provision of Primary Health Care in Bangladesh', August, 2003, in Paper presented at the Conference on Development Research at Lund University, <http://www.nek.lu.se/publications/workpap/Papers/WP03_18.pdf> (Accessed on 30.05.2011), p.10.

31 Islam, Mohammad Shafiqul and Ullah, Mohammad Woli, supra note 27, p.10.
} 
Secondary health care facilities are available at the districts level hospitals. At present there are 36 hospitals with bed capacity of 50 each, 21 hospitals have 100 beds each, two have 150 each and one hospital in Narayanganj has 200 bed capacities. All hospitals deal with referred cases of the thanas for further improved treatment. However, these hospitals have limited specialist, diagnostic and laboratory services. District hospitals provide door and out-door services. Eighty percent beds of these hospitals are free of cost. Apart from these hospitals there are 24 school health clinics, 44 tuberculosis (TB) clinics and 72 urban dispensaries at district level which provide only out-door services. At the district level, the Civil Surgeon (CS) acts as the district health manager, who also functions as the superintendent of the district hospital. The civil surgeon is responsible for all kind of development and administration of health service in the district32.

\subsubsection{Upazila Level}

At the sub-district (Thana or Upazila) level, 460 Thana Health Complexes, comprising 31-bed inpatient facilities with outpatient and supporting services, provide both primary and secondary care for a population of between 100,000 and 400,000 people $^{33}$. Some UHC have over 50 beds. Many UHC Units have a package service called "comprehensive emergency obstetric care services" (EOC) available, with an expert gynaecologist, an anaesthetist and skilled support nurses on duty round-the-clock and basic laboratory facilities ${ }^{34}$. Services delivered at thana level represents 31 per cent of the government sector, but only 9 per cent of expenditure in the sector as a whole. Within Thanas, 3,275 Health and Family Welfare Centres serve Unions covering between 25,000 and 30,000 people. Municipalities are responsible for publicly financed health service provision in urban areas ${ }^{35}$.

\subsubsection{Union Level}

At this level health care services are delivery through both Union sub-centers (USC) and Union Health and Family Welfare Center (UHFWC). This is the smallest and most peripheral healthcare service unit having sub-center which provides out-patient services for injuries, wounds and ailments and with no diagnostic, surgical or bed facilities. These health centers provide first static health care facilities. About fifteen health and family planning personnel are managing the static health care facility and are rendering domiciliary services at the union level. A USC is managed by one medical officer, one medical assistant, one pharmacist and other support staff while FWC is managed by one medical assistant, one family welfare visitor, one pharmacist and other support staff ${ }^{36}$. Each Union Health Centers has an available staff comprising of a Medical Assistant, trained for three years in disease prevention, health education, and basic first aid, and a Family Welfare Visitor, who receives 18 months of training in family planning, reproductive health, and postnatal and prenatal care. These health centers offer, other than general health services, minimal reproductive, maternal, and child health care services for the local people free of cost. The number of physicians and registered nurses relative to population is 241 and 136 respectively per million people while number of hospitals available for a million people is 10 and the availability of hospital beds is one for about 4000 people $^{37}$.

\subsubsection{Village Level}

At the village level, there are community clinics; satellite clinics as most peripheral level health services facilities with a view to provide minimum care. From time to time, this health services are delivered (say once a month). The patients are motivated to go and take services there like EPI, Oral Re-hydration Therapy (ORT) services, awareness rising about health, sanitation, nutrition communicable diseases etc. The staffing pattern of the clinic is one health assistant, one family welfare visitor, and one assistant health inspector ${ }^{38}$.

\footnotetext{
32 Islam, Mohammad Shafiqul and Ullah, Mohammad Woli, supra note 27, p.11.

${ }^{33}$ Ahmad, Alia, supra note, 30, p.10.

${ }^{34}$ Health System in Bangladesh, available at <http://www.whoban.org/health_system_bangladesh.html> (Accessed on 23.05.2011).

${ }^{35} \mathrm{Ahmad}$, Alia, supra note, 30, p.11.

${ }^{36}$ Islam, Mohammad Shafiqul and Ullah, Mohammad Woli, supra note 27, p.10.

${ }^{37}$ Rahman, M Shamsur and Ashaduzzaman, Abu Shahin M., 'Poor People's Access to Health Services in Bangladesh: Focusing on the Issues of Inequality' in Workshop on Health Care for the Poor in Asia <http://www.napsipag.org/pdf/Issues_of_Inequality.pdf> (Accessed on 29.05.2011), pp.3 \&.4.

38 Islam, Mohammad Shafiqul and Ullah, Mohammad Woli, supra note 27, p.9.
} 


\subsection{Private}

There are private physicians and increasing number of service sites, especially in urban areas. There are innumerous private clinics spread throughout the country even at district and Upazila levels to offer health service in privatized form. These clinics are highly charged and work fully on commercial basis. Solvent people prefer private clinics for quality service, which they think is absent in the public hospitals. In the recent years a number of international level private hospitals have been established in Bangladesh, more specifically, in the capital city of Dhaka. Some of those are established with collaboration between the multinational companies and the local entrepreneurs ${ }^{39}$.

\section{Performance Picture}

\subsection{Infrastructural Development}

Improvements in infrastructure development and construction of new facilities are continuing in the HNP sector through required investment. 198 health complexes out of 419 have been upgraded to 50 beds. Upgradation of 103 Upazila health complexes is continuing. At union level to serve health care 3,780 health and family welfare centers have been established. Rest of 322 union health and family welfare centre to be established. Through expansion of existing hospitals, four medical colleges and three IHT have been set up. Present government allocated 180 ambulances in different hospitals and health institutes. On the basis of principle of establishing one community clinic for every 6,000 population in rural areas, government is establishing 13,500 community clinics. Measures have taken to operational 10,723 community clinics. A project has been undertaken for ensuring health services to the rural people through community clinics by constructing another 2,876 new community clinics. Appointment of 13,500 Community health care providers is under process. Initiatives have been taken to set up Solar panel for uninterrupted electricity supply to ensure health services at community clinic ${ }^{40}$.

\subsection{Progress in the Pharmacy Sector}

The pharma sector of Bangladesh has been turned into a fast growing one due to the appropriate policy and incentives of the present Government. At present the pharmaceutical sector is meeting the $97 \%$ local demand which is amounting to Taka 7000 crore. This is gradually increasing \& expected to reach 8500 crore within next 2-3 years. After meeting $97 \%$ of local demands of medicine we are exporting our pharma products to 79 countries of the world including USA \& UK. Very specialised product like Anticancer, Hormone, Insulin etc. are produced locally. Bangladesh will be able to produce human vaccine very soon. If this trend of growth continues, it is expected that the growth rate in the pharma sector will increase upto $15 \%$ from 13.5\%. The present Government has given utmost importance to the drug sector and accordingly raised the status of the Directorate of Drug Administration to that of Directorate General of Drug Administration. To raise the Drug Administration to an international standard training has been conducted by WHO consultant to the officers of Drug Administration. Action has been taken to update the National Drug Policy 2005. To make the country self sufficient in Raw material productions \& to decrease import dependence, Government has taken initiative to establish an Active Pharmaceutical Ingredient (API) Park which is under process. ${ }^{41}$

\subsection{Water Supply and Sanitation}

Bangladesh has made tremendous strides in improving access to safe water. According to a recent estimate, nearly $96 \%$ of all people drink water from either tube-well or piped water, which can be considered safe, compared to just 37 per cent in the early 1980s. The biggest improvement in this regard occurred in the 1980s, so that by the early 1990s almost 90 per cent of households already had access to safe water. However, water related diseases remain the major cause of mortality and morbidity, because 'safe' is only a relative term; much of the water that is used for drinking purposes is not free from germs, and as a recent study shows more than 90 per cent of households drink completely untreated water.

\footnotetext{
39 Rahman, M Shamsur and Ashaduzzaman, Abu Shahin M., supra note, 37, p. 4.

${ }^{40}$ Ministry of Health and Family Welfare Performance Report, 2009-2010, available at <http://www.mohfw.gov.bd/index.php?option =com_content\&view=article\&id=112\%3Aperformance-report-2009-2010-of-mohafw\&catid=72\%3Aperformance-report-2009-2010-ofmohafw\&ltemid=\&lang=en > (Accessed on 06.06.2011), p.5.

$41 \mathrm{lbid}$, p. 6.
} 
Moreover, only 16 per cent of all households use tubewell or piped water for all domestic purposes, which is a further reason for the spread of waterborne diseases. Sanitation coverage has also expanded, but not as much as safe water. According to a recent survey of the Bureau of Statistics, just over 40 per cent of all households had access to watersealed latrines; more than 50 per cent had latrines that were not water-sealed, and about 7.5 per cent households had no latrines at all. A comparison of Bangladesh Health and Demographic Surveys in successive years reveals, however, that most of the improvement in sanitation that has occurred in the recent past has taken the form of moving people away from open disposal of excreta to uncovered latrines rather than giving them access to truly modern sanitation (watersealed). Thus, households with no access to latrines at all have come down from 30 per cent in 1993/94 to 7.5 per cent in 2007, but the proportion of households with access to modern sanitation has increased only marginally from 25 per cent to 29 per cent during the same period. At the same time, the proportion of households with uncovered latrines has gone up sharply from 45 per cent to 64 per cent ${ }^{42}$.

\subsection{Life Expectancy and Mortality}

In the last two decades, life expectation in Bangladesh has increased by nearly 11 years - going up from 56 years in 1990-91 to almost 67 years in 2007-08. The urban population has had a distinct advantage over their rural counterparts in terms of living longer, but the advantage has diminished over time-falling from an excess of almost 4 years in the early 1990s to just about 2 years in 2007-08. The overall decline in the crude death rate (CDR), the rise in life expectation and the narrowing of the gap between rural and urban areas can be explained in terms of improved access to health services and increased awareness about preventive and curative health care that has increasingly encompassed the rural people as well. Perhaps the most important part of the decline in overall mortality, and the resulting increase in life expectation, can be attributed to an impressive decline in infant and child mortality in recent decades. Unlike the overall mortality rate (CDR), infant mortality rate (IMR) started to decline already in the 1980scoming down from 112 per thousand live births in 1984-85 to 92 per thousand in 1990-91, and the rate of decline has accelerated since then. In the last two decades, infant mortality rate has been more than halved-from 92 per thousand in 1990-91 to around 41 in 2007-08. The decline in under-5 mortality rate during the same period has been even more impressive-falling from 148 live births in 1990-91 to 55 in 2007-08 (Table V). Rural areas have had a distinctly higher infant mortality rate throughout the period under consideration, but the rural-urban differential has narrowed remarkably in recent years (Table V). Excess death of infants in rural areas compared to urban areas was at least 25 in the early 1990s; but by 2007-08 the differential had all but disappeared ${ }^{43}$.

\section{Problems Lying in the Way of Access to Health Service}

Though there has been progress in the certain areas of health, there is still a wide variety of factors causing serious problems to the enjoyment of the right to health. On analysis of information on health facilities and provisioning of health service etc. it has been found that there are many problems lying on the way of enjoyment of the right to health in Bangladesh. Some of such problems are as follows:

\subsection{Neonatal mortality}

Though Child health in general has been improving, with a declining mortality trend having been observed in the last decade, the declining trend in infants and neonate mortality over the past few years is not significant enough, and there is still unacceptably high level of neonatal mortality which consequently contributes disproportionately to overall infant mortality. The neonatal mortality rate, a major contributor to the burden of infant mortality, is still high at 36 per 1000 live births (SVRS 2004). Acute respiratory infections alone cause $23 \%$ of deaths in children aged below five years. Furthermore, nearly half of all children (47\%) are moderately underweight and one-third suffers from stunting (BDHS 2004) ${ }^{44}$. The immunization program has been recognized for its sustained high coverage; however, only $71 \%$ of infants are fully immunized. ${ }^{45}$

\footnotetext{
${ }^{42}$ Chowdhury, Omar Haider, and Osmani, S.R., Supra note 2, pp.18 \& 19.

${ }^{43}$ Chowdhury, Omar Haider, and Osmani, S.R., Supra note 2, pp. 25 \& 26.

${ }^{44}$ WHO Country Co-operation Strategy 2008-2013 Bangladesh, available at <http://203.90.70.117/PDS_DOCS/B0680.pdf > (Accessed on 15.06.2011), p.18.

$45 \mathrm{Ibid}$, p.10.
} 


\subsection{Communicable and non communicable diseases}

Communicable diseases continue to be a prevalent problem and non-communicable diseases show a rising trend. The first case of Human Immunodeficiency Virus/Acquired Immune Deficiency Syndrome (HIVIAIDS) was detected in Bangladesh in 1989. Till December 2006 the cumulative number of reported cases of HIV had reached 874. According to the official report, the number of HIV-related deaths is 109 up to December 2006. However, the estimated total number of HIV infections as of December 2006 was 7500 according to the National AIDS and Sexual Transmitted Disease Programme (NASP) 2006. Considering the high prevalence of the disease in neighbouring countries, the social stigma and also the limited access to HIV counselling and testing services, Bangladesh faces the risk of an HIVIAIDS epidemic. A recent survey indicated that the country is now going through the phase of a "concentrated epidemic" with a nationwide prevalence of $7 \%$ among the intravenous drug users (IDUs) ${ }^{46}$. The extensive levels of arsenic contamination of the shallow groundwater puts an estimated 20 million people at risk of arsenicosis. It is estimated that by 2010 noncommunicable diseases (NCDs) will be responsible for $59 \%$ of deaths compared to $40 \%$ in 1990 . Underlying factors that contribute to the increasing burden of NCDs include unplanned urbanization, changing dietary habits, unregulated tobacco consumption, air pollution, road traffic injury and lack of awareness about healthy behaviour. Tobacco in particular is a major risk factor, having caused 57000 deaths and 382000 disabilities in 2004 alone ${ }^{47}$.

\subsection{Maternal Mortality Remains Unacceptably High}

Although there has been during the last decade a steady decline in maternal mortality, the figures still remain unacceptably high (Figure 2). Lack of available maternal health services at and around birth is one of the contributing factors to high maternal mortality. The proportion of deliveries assisted by skilled personnel (skilled birth attendants) was found to be only $13.4 \%$, with $9.4 \%$ in rural and $29.6 \%$ in urban areas, according to the Bangladesh Demographic and Health Survey (BDHS) 2004. Leading causes of maternal mortality are haemorrhage, abortion, injuries, eclampsia, sepsis and obstructed labour. In spite of continuing efforts by the government's micronutrient programme, maternal malnutrition is an underlying cause of many deaths. Nearly half of all pregnant women suffer from malnutrition and anaemia that contributes to low-birth-weight babies and neonatal mortality. Innovative, but nevertheless sporadic, household-level nutrition security initiatives such as kitchen gardens and backyard poultry have not resulted in a significant improvement of the nutritional status of mothers. Micronutrient supplementation has still not been successfully addressed ${ }^{48}$.

\subsection{Chronic Shortage and Inequitable Distribution of Health Resources}

Bangladesh has been identified as one of 57 countries with a critical shortage of the health workforce (doctors, nurses and midwives number below 2.28 per 1000 population). The nurses to population ratio of 0.14 per 1000 and nurses to doctors' ratio of 1:1.85 are among the lowest in the world (Figure 5) ${ }^{49}$. Another estimate reveals that the density of medical workers (doctors, nurses, and midwives together) is only 0.58 per 1,000 people in Bangladesh, whereas international evidence suggests that the optimal density is about 2.5. The current density in Bangladesh is thus only about a quarter of what it should be. The distribution of different categories of medical workers is completely lopsided. For example, according to international best practice, the nurse-doctor ratio should be 2:1, but the current situation in Bangladesh is completely the reverse-with twice as many registered doctors as nurses ${ }^{50}$. Based on low-income countries' average, Bangladesh currently has a shortfall of 60,000 physicians. The shortfall is going to increase further as the population increases. At the same time, human resource is unevenly distributed across the country with little resources in rural areas ${ }^{51}$. Thus, all such problems are further aggravated by the fact that the availability of existing

\footnotetext{
46 Ibid, p.19.

47 Ibid, p.11.

$48 \mathrm{lbid}, \mathrm{p} .17$.

49 Ibid, p. 25.

${ }^{50}$ Chowdhury, Omar Haider, and Osmani, S.R. supra note 2, p.222.

51 Challenges for Health System in Bangladesh in Bangladesh Health System in Transition: Selected Articles by Dr. Anwar Islam published at James P. Grant School of Public Health BRAC University, Monograph Series: 11, available at <http://www.bracuniversity.net/\&S/sph/publications/reports/monograph/Monograph\%20Series\%20-11.pdf > (Accessed on 15.06.2011), p.2, 3rd para.
} 
facilities is highly skewed towards the urban sector-with only about 16 per cent of qualified doctors practising in rural areas where the majority of population still live (BHW 2008) ${ }^{52}$. Besides, absenteeism of key health human resources ("ghost" physicians) often make matters much worse. Lack of drugs, supplies and other facilities also plague the heath complexes. As a result, our publicly funded health care system is used by only 25 per cent of the population ${ }^{53}$.

\subsection{Inadequate Budget Allocation}

The total health expenditure constitutes 3.2\% of the national Gross Domestic Product (GDP) (National Health Accounts $[\mathrm{NHA}]$ 2003). The sectoral share of the GDP of the health sector (at 2000-01 prices) has increased only marginally from 0.71\% in 1998-1999 to 0.83\% in 2004-2005 (Public Expenditure Review [PER] 2003- 2004). Health expenditure in Bangladesh, at US\$ 12.16 per person per year (NHA 2003), is far below the minimum expenditure for scaling up a set of essential health interventions in the country. The government's health expenditure is only around US\$ 4 per capita per annum (NHA 2003) and prospects for its substantial increase, are limited. An effective increase in the public health allocation to meet the minimum needs of the population is a challenging task ${ }^{54}$.

\subsection{Little progress in reducing malnutrition among children:}

We have made little progress in reducing malnutrition among children. The percentage of underweight children aged 659 months remained more than 45 per cent since mid-1990s. Moreover, 30 per cent of our population suffer from malnutrition. At 320 per 100,000 live births, the maternal mortality ratio also remains stubbornly high in Bangladesh. A precondition for reducing maternal mortality is to ensure skilled birth attendants during delivery. Sadly, we have achieved precious little in this respect. In 1995, only 10 per cent of deliveries were done by skilled birth attendants. The figure increased to 12 per cent in 2000 and to 17.8 per cent in 2007. In other words, unskilled health workers are handling more than 80per cent of childbirths. Not surprisingly, a high 85 per cent of births in Bangladesh continue to take place at home, attended by unskilled individuals who can neither recognize pregnancy-related complications nor provide effective interventions ${ }^{55}$.

\subsection{Income Inequity and Disparities in Access to Health}

Income inequity and disparities in access to health and other services continue to persist in Bangladesh. More than 40 per cent of our population live on an income of less than a $\$ 1$ a day. Almost 50 per cent of our population live below the national poverty line. More importantly, income inequity seems to be rising in Bangladesh. Income share held by the lowest 20 per cent of the population declined from 9.5 per cent in 1990 to 8.6 per cent in 2000 and to 7.3 per cent in 2005. Clearly, more and more wealth is being concentrated in fewer and fewer hands. As the poor has less access to health care services, they share a disproportionate burden of disease and deprivation. According to the 2007 Bangladesh Demographic and Health Survey, among the lowest wealth quintile (the poorest segment of the population), skilled personnel attended only 4.5 per cent of deliveries. The corresponding figure for the highest wealth quintile (the richest segment of the population) was 60.1 per cent. Likewise, while only 28.3 per cent of women from the lowest wealth quintile received antenatal care, 91 per cent of women from the highest wealth quintile did so. The survey also shows that only 20.3 per cent of children from the lowest wealth quintile received treatment for Acute Respiratory Infection, while the corresponding figure for the highest wealth quintile was 58.1 per cent. Disparities between the rich and poor continue to persist in other areas too including malnutrition, anaemia during pregnancy among women, and the percentage of fully vaccinated children ${ }^{56}$.

\subsection{Profit Motivated Health Service}

Bangladesh has a bourgeoning private sector providing health services. Pharmacies, clinics, diagnostic centres and modern tertiary care hospitals constitute the landscape for a robust for-profit private sector in health. It is growing at a

\footnotetext{
52 Chowdhury, Omar Haider, and Osmani, S.R. (March-June 2010,) supra note 2,p.222.

${ }^{53}$ Islam , Dr. Anwar, supra note, 51,p.2, 3rd para.

54 Ibid, p. 27.

55 Islam , Dr. Anwar, supra note 51, p.1.

$56 \mathrm{Ibid}$, p.2.
} 
rate of 15 per cent each year. On the other hand, our informal health care providers - from Hakims and Ayurveds to pharmacists and various kinds of unqualified "village doctors" - outnumber the "formal" qualified service providers by 12 to 1. From time to time, newspapers flash horror stories about some of these for-profit clinics - from unnecessary surgeries to unqualified surgeons. Stories of re-use of used syringes, using unsafe blood for transfusion and almost total negligence to medical waste management by some of these clinics and diagnostic centers often make the news. Despite these periodic horror stories, most of the people regularly use these private sector institutions for their health care ${ }^{57}$.

\subsection{Corruption in the Health Sector}

The health sector is bedeviled by lack of accountability of service providers including medical practitioners in public hospitals, who are allegedly more involved in private practice than ${ }^{58}$ their commitment and duties as employees of the Government. They are also reportedly linked with other types of malpractices such as sending patients to private clinics where they have business interests. Other corruption indicators include misappropriation of medicine supplied in hospitals and health centers for the poor patients; poor-quality food provided to patients; pervasive influence of middleman and extortionists in hospitals often with the connivance of members of the medical staff at various levels; and above all, in many cases corrupt hospital management. Corruption is deep and pervasive in the entire public health services sector including the hospitals attached to medical colleges, regional and sub-regional public hospitals and clinics, offices of the Civil Surgeon, and various population planning delivery outlets. Successive reports based on TIB Corruption Database (2000, 2001, 2002, and 2003) and the Household Corruption Survey 2002 and 2005 identified the health sector as the fourth most corrupt sector. According to the Household Corruption Survey of 2005, 47.56 percent of the respondents failed to get admitted into the hospitals through the normal prescribed procedure and had to take recourse to 'alternative means', which in case of 56 percent meant payment of bribery. Nearly 30 percent of the respondents seeking services from outdoor of the hospitals had to make unauthorized payments at an average rate of Taka 60 to doctors while $20 \%$ of the indoor patients had to bribe at an average rate of Taka 478 to doctors of public hospitals for receiving medical advice. The 2005 Household Corruption Survey further revealed that $37 \%$ of the patients who had to undergo a surgery were forced to pay at the rate of Taka 1420 as bribes. $57 \%$ patients had to pay at the rate of Taka 516 as bribe for getting an X-Ray done. In addition, $60 \%$ of the patients who had to take a pathological test had to pay at the rate of Taka 410 as bribes. The amount of bribe paid for delivery of new-born babies is between Taka one to five thousand. A 2002 TIB Report Card Survey on health revealed that $49.5 \%$ of the patients complained that the doctors did not pay due attention to patients. The survey also revealed that only $34 \%$ of the patients are satisfied with the service they received from the doctors. Only $1 \%$ patients are satisfied with the degree of cleanliness of the government hospitals. The TIB report card survey 2005 on health services in Rajshahi area revealed that patients are victims of 13 other types of bribing, which include: unauthorized payments for bed allocation, using ${ }^{59}$ trolleys, getting supplies like saline, bandage materials, food from the canteen, and medicine from the hospital pharmacy all of which are supposed to be free of cost. Patients suffer long delays in getting attention of doctors who often prefer patients to visit them in private clinics where they are involved in practice on commercial basis. Patients are also forced to buy medicines or conduct tests from pharmacies or clinics which have business relationships with doctors and other staff of the public hospitals. Among respondents affected by corruption in hospitals, $56 \%$ reported corruption by doctors, $36 \%$ reported corruption by hospital staff, and $5 \%$ by nurses. Of those who were affected by corruption in hospitals, $61 \%$ respondents said that this was done directly by the service providers, $17 \%$ said corruption was practiced indirectly through a third party. All patients complained that they had to wait for long time in the hospitals as the doctors are very irregular and do not attend the hospitals on time, apparently because they remain busy with their private practice. The survey revealed that per capita annual spending on bribery for those who received service in government hospitals was about Taka 1847. In rural areas, the expense is Taka 1711, and in urban areas it is Taka 2256. On the basis the Household Corruption Survey 2005, the annual amount of bribe collected by health officials was estimated to be Taka 1,140 million, which is 5.24 percent of annual public expenditure on health. Other complains of corruption include: mismanagement, unavailability of the staff including duty doctors, lack of professional attitude, negligence of duty by the cleaning and other support staff. Like in education, implications of corruption in the health sector on the poor are also much more severe. Table 2 below shows the percentage of surveyed population forced to make unauthorized payments for access to health. In both types of

\footnotetext{
57 Id. pp. 2 \& 3, $3^{\text {rd }} \& 1^{\text {st }}$ paras respectively. \&HumanSecurity091205.pdf > (Accessed on 06.10.2011), p.14.

59 lbid, p.15.
}

58 Iftekharuzzaman, Corruption and Human Insecurity in Bangladesh <http://www.ti-bangladesh.org/research/Corruption 
unauthorized payments the highest proportion of victims of corruption (42.4 and 43.6 percent) are in the category of respondents living below daily income of less than 1 dollar. The next highest category of victims (35.1 and 35.4 percent) are in the income category of $\$ 1$-plus to $\$ 2$, which means that between more than 77 percent of victims of corruption in health are living on a daily income of less than $\$ 2^{60}$.

\subsection{Poverty}

Since independence in 1971, Bangladesh is struggling to emerge from the realm of poverty and improve the standard of living of her population. But in spite of receiving large amount of foreign aid it has not been possible to achieve the goal and the rate of poverty reduction is still low. In the last five years the average rate of poverty reduction is about 0.52 percent per year, while the rate is only 0.32 percent per year for rural areas during $1999-2004$. The poor people are neither capable of bearing their health expenditure nor conscious of health, nutrition, and sanitation. ${ }^{61}$.

\subsection{Poor Health Knowledge}

Another setback in the public health care system is that most of the projects and programs are based on curative measures, which is much expensive and more complicated. Practices of healthy lifestyles and nutrition habits; health education and health research; prevention programs etc. are negligible and, in many areas, absent in Bangladesh. We see that most of the treatment and equipment facilities prevailing in our hospitals are based on western types of diseases and the indigenous disease-based treatment facilities are underdeveloped in our hospitals. While the medical practitioner remaining unnecessarily biased to west centric treatment system ignoring our local ethos, the poor people also do not know their rights ${ }^{62}$.

\subsection{Administrative Mismanagement}

There are also administrative mismanagement and deficiency of medicine and medical facilities for the majority of people living at the rural areas. In the recent years physical facilities have deteriorated in most Upazila Health Complexes. Modern technologies are not available in those hospitals and in some cases existing high-tech equipments are ruined due to non-operation in short of technicians. Training opportunities for nurses, laboratory x-ray and other health sectors technicians are very much limited. Bangladesh has the scarcity of health personnel with only 246 physicians and 136 nurses per one million people. Poor staff practices is a major problem in many Upazila and Union Health and Family Planning Complexes with high levels of absenteeism, informal user-charging, unwilling to work, regarding postings as 'punishment' etc. Moreover, wrong treatment, negligence towards patients, non-attentiveness, irresponsibility, absence from duty, and unwillingness of doctors to stay at rural areas and small towns are the other problems in the public health sector of Bangladesh. There are also problems related to supplies, equipment, beds, ambulance services, proper referral services etc. Hospital management is said to be very poor in Bangladesh. There is little scope for training courses for the health administrator and on the contrary the trained officers are not posted in the respective places. Qualified doctors are not posted in the right place and in most cases posting is influenced, and sometimes, decided by BMA (Bangladesh Medical Association), the highly politicized professional organization of the physicians. The professional organization is also blamed for influencing health administration and working against people's interest. Professional regulation in medicine, nursing and dentistry is much little in Bangladesh and mechanism to bring the service provider under accountability is also very poor here. As a result these hospitals and health centers no longer enjoy public confidence and are underused ${ }^{63}$.

\subsection{Crisis in Personnel System}

The low level salaries offered to the doctors have led them to private practice. Lack of promotion prospects reduces their motivation and working inspiration. There are instances that doctors are taking retirement as medical officers, the same post they have joined in nearly three decades ago. For all these reasons a recent study showed that $76 \%$ of doctors do

\footnotetext{
60 Ibid, p. 16.

${ }^{61}$ Rahman, Shamsur and others, supra note 37, p.5.

62 Ibid, p.5.

${ }^{63}$ Id. pp. 6 \& 7 .
} 
not remain at their posting places. They don't receive further training and their medical knowledge is not up-to-date to treat the modern diseases with changing methods of treatment. Doctors are allowed to private practice, which leads them towards more income and diverts them from their hospital duties. Doctors of the public hospitals are blamed for referring patients to paid treatment or paid operation in their own private clinics or even receive illegal charge for treating privately during hospital hours and within hospital premises. With all these things there prevails a vicious circle whereby their vested interests keep public sector service quality relatively low ${ }^{64}$.

\subsection{Monitoring and Accountability}

The public hospitals lack proper monitoring mechanism and system of accountability. Absence of strong local government system has made the public hospitals and health centers guardian-less. Practice of trade unionism by the lower employees, illegal and unethical practices by the contractors (food and other commodity suppliers etc.), organized pressure from the nurses community, irritation created by the medical representatives (sale agents of the pharmaceutical companies) and the dalals (agents) of the private clinics have made the hospital environment polluted where the interests of the patients is meagerly protected. The doctors are also blamed for prescribing unnecessary examination and diagnosis suggestion to the patients since they get commission from the diagnosis centers. There is currently neither monitoring mechanism for seeking redress against the violation of right to health, nor for holding the violators accountable. The doctors and the other service providers, therefore, get immunity of their negligence, inefficiency or wrong treatment causing health hazards and sufferings to the patients ${ }^{65}$.

\section{Concluding Remarks with Recommendations}

The right to health is embedded in the Constitution of Bangladesh. This implies that the government acknowledges its obligation to progressively realize the highest attainable standard of health for the entire population. The National Health policy 2000 also confirmed the state's constitutional obligation of delivering health services to all. But there are many obstacles that hinder the access of the poor to health service in Bangladesh. In Bangladesh 60 percent of the population lives below poverty line and although the poverty situation has slightly improved, the rich-poor gap has widened over the years, and there are also multiple cause of the limited access of the poor to health services. Shortages of stuff, hospital beds, medicine and equipment and the poor maintenance of health infrastructure are notable. Although the total number of hospitals and hospital beds doubled between 1980 and 2000 (from one bed per 4000 to one bed per 3500 people), total availability remains insufficient by far. Besides, most of the increase occurred within the private sector, which the poor cannot afford. Many people, especially the poor, depend on traditional health service providers. Mismanagement and discrimination of the poor in health services are a common phenomenon. Excessive fees and often official payments are being requested for health services and people from higher income groups receive preferential treatment. Health service users feel there is a lack of accountability for service providers, they have nowhere to turn to with their complaints. Strong directives and example setting from the top are necessary to halt preferential treatment for elites in health services.

Another issue is that physicians working in public health services refer patients to their private practices for (paid) treatment or operate their own private clinic during hospitals hours and hospital premises. Health service providers, on the other hand, are hindered by complex administrative rules, highly centralized decision-making, political interference and shortage of supplies. There is lack of training opportunities for nurses' laboratory X-ray and other health sectors technician. In addition, the population at large is generally ignorant about healthy life styles and nutrition habits and in many areas health education and prevention program are absent. In order to overcome these difficulties and to transform the concept of health as human right into reality an integrated approach of co-operation from different quarters should be taken. Thus the following suggestions may be taken into account:

1. The government should improve knowledge and understanding of health which is an indispensible step in promoting health supportive action. Creating social, economic and environmental conditions that are conductive to health is also essential. These can become a reality only when there is a heightened awareness of health matters among policy makers, politicians, economic planners and the public alike and when this awareness is transformed into policies, legislation and favorable allocation of resources for health. For it, the

\footnotetext{
$64 \mathrm{Id}, \mathrm{p} .7$.

65 Id. p.7.
} 
strategy by way of advocacy for health may be adopted in order to generate pubic demand, place health issue on the public agenda and effectively convince those who are influential (i.e., policy makers, elected representatives, professionals, political and religious leaders and interest groups) to act in support of health in their respective professional field. For this purpose NGOs and mass-media may play a vital role in raising awareness among social support from the ordinary citizens about the right to health and their entitlement; because such awareness and support are the precondition of the empowerment of the people to lead the concerned influential to the right direction.

2. Priorities and approaches to health solutions must be individualized and contextualized within local realities. In doing so, the government should decentralize the public health system and may experimentally allow community based organizations to manage rural health centers under direct supervision of the local governments. Furthermore, budget allocations for the respective regions must be made on the basis of need so that each individual has an access to affordable health care. For this purpose the government should increase its health expenditure by allocating $5 \%$ of its GNP as set by WHO on Health care and revise the budgeting process and redistribute resources by reducing its expenditure in unproductive sector for example, military expenditure and by allocating resources on the basis of the actual health situation and health needs and in this respect the donors can sanction with the restriction that an optimum amount of money must go to the health sector and should pressure the government to introduce participatory budgeting in the health sector.

3. Poverty is the worst enemy of the development of health and other economic, social and cultural rights. Poverty cannot be eradicated as long as the economics of the developing and least developed countries like Bangladesh are crippled by external debt. Soft loan and debt forgiveness for countries crippled by external death makes sense economically and for serving human needs. This way, the global economy must serve human needs, otherwise breach of peace caused by social injustice any where remains a threat to peace everywhere.

4. The government must adopt an all-out strategy to combat corruption with the active collaboration from the civil society groups at micro meso and national level. In this espect, an institutional framework of civil society monitoring mechanism should be developed in order to lessen corruption prevailing in the health sector significantly and thereby ensure accountability of the health service providers. In addition, academic syllabus may also be revised in order to include therein the different topics of corruption.

5. The government must ensure non-discrimination in the provision of health service, and also that the poor can get access to services provided by private health practitioners through differential prancing, e.g., in the form of subsidy or tax relaxation or direct progressive taxation and charges.

6. The government should introduce health insurance in a pro-poor manner and institutionalize participatory decision-making and monitoring mechanism for accountability and ask all health service providing institutes to develop their own charters highlighting their vision and mission, details of service provisions and details of grievance redressing mechanisms. A citizen's charter, by definition, should be developed through the participation of stakeholders. Without it the charter is just a statement of intent rather than a live, meaningful contract between the state and the citizens which is what it is meant to be. Citizens should also be engaged in monitoring compliance with the charter and during review of the charter which should take periodically.

\section{References}

\section{Books}

Farooque, Mohiuddin and Hasan, S. Rizwana: Laws Regulating Environment in Bangladesh, 2nd ed. Dhaka, published by Bangladesh Environmental Lawyers Association, 2004.

Kumar, Avanish, Human Right to Health, 1st edition, Satayam Law International , new Delhi, India, 2007. Islam, Mahmudul, Constitutional Law of Bangladesh, 2nd ed. Dhaka, 2002.

\section{Articles}

Chowdhury, Omar Haider, and Osmani, S.R. (March-June 2010,) 'Towards Achieving the Right to Health: the Case for Bangladesh', The Bangladesh Development Studies, Vol. XXXIII, Nos. 1 \& 2, <http://www.bids.org.bd/bds/33-1\&2/Omar _H_\&_S_R_Osmani.pdf> (Accessed on 29.05.2011) 
Islam, Mohammad Shafiqul and Ullah, Mohammad Woli, (June 2009) 'People's Participation in Health Services: A Study of Bangladesh's Rural Health Complex' in Bangladesh Development Research Working Paper Series, BDRWPS 7, $<$ http://www.bangladeshstudies.org/files/WPS_no7.pdf > (Accessed on 26.05.2011).

Ahmad, Alia, 'Provision of Primary Health Care in Bangladesh', August, 2003, in Paper presented at the Conference on Development Research at Lund University, <http://www.nek.lu.se/publications/workpap/Papers/WP03_18.pdf> (Accessed on 30.05.2011).

Rahman, M Shamsur and Ashaduzzaman, Abu Shahin M., 'Poor People's Access to Health Services in Bangladesh: Focusing on the Issues of Inequality' in Workshop on Health Care for the Poor in Asia, <http://www.napsipag.org/pdf/Issues_of_Inequality.pdf> (Accessed on 29.05.2011).

Islam, Dr. Anwar, Challenges for Health System in Bangladesh in Bangladesh Health System in Transition: Selected Articles by published at James P. Grant School of Public Health BRAC University, Monograph Series: 11, <http://www.bracuniversity.net /I\&S/sph/publications/reports/monograph/Monograph\%20Series\%20-11.pdf> (Accessed on 15.06.2011).

Iftekharuzzaman, Corruption and Human Insecurity in Bangladesh, <http://www.ti-bangladesh.org/research/Corruption \&HumanSecurity091205.pdf > (Accessed on 06.10.2011).

\section{Cases}

Kudrat-E-Elahi Vs. Bangladesh, 44 DLR (AD) 319.

Kudrat-E-Elahi Vs. Bangladesh, 44 DLR (AD) 331.

Wahab vs. Secretary, Ministry of Land, 1 MLR 338.

Mohiuddin Farooque Vs. Bangladesh, 48 DLR, 438

Munn Vs. People of Illinois, 94 US 113.

Keshavnand Bharti Vs. State of Kerala, (1973) 4 sec 225.

Bandhua Mukti Morcha Vs. UOI, AIR 1984 SC. 812.

Consumer Education and Research Centre Vs. UOI, AIR, 1995 SC 636.

Paschim Bangla Khet Mazdoor Samity and Others Vs. State of West Bengal and Another, (1996), $4 \mathrm{sec} 37$.

\section{Other Materials}

Ministry of Health and Family Welfare Performance Report, 2009-2010, <http://www.mohfw.gov.bd/index.php?option=com_content \&view=article\&id=112\%3Aperformance-report-2009-2010-of-mohafw\&catid=72\%3Aperformance-report-2009-2010-ofmohafw\&ltemid=\&lang=en > (Accessed on 06.06.2011).

WHO Country Co-operation Strategy 2008-2013 Bangladesh, <http://203.90.70.117/PDS_DOCS/B0680.pdf > (Accessed on 15.06.2011).

Health System in Bangladesh, <http://www.whoban.org/health_system_bangladesh.html> (Accessed on 23.05.2011). 